\title{
A DESCONSTRUÇÃO DO EU EM FERNANDO PESSOA
}

\author{
Cristiane Prando Martini Simeoni ${ }^{1}$
}

RESUMO: A presente contempla a desconstrução do eu em Fernando Pessoa, autor de um silêncio sussurrante, olhar desassossegante de alguém que buscou explicar as questões tangentes de sua época. A mesma propõe um diálogo com a poética de um de seus heterônimos mais perturbados: Álvaro de Campos.

PALAVRAS-CHAVE: Niilismo; desconstrução do Eu; heterônimos.

\begin{abstract}
This essay contemplates the deconstruction of the "I" in Fernando Pessoa, author of a mild silence, a restless view of someone who searched to explain the tangent issues of his time. It also considers a dialog with the poetical work of one of Pessoa's most insane heteronyms: Alvaro De Campos.
\end{abstract}

KEYWORDS: Nihilism; deconstruction of the "I"; heteronyms.

\footnotetext{
${ }^{1}$ Mestranda em Letras-Literatura Portuguesa-(USP)
} 
A criação heteronímica de Fernando Pessoa nos faz pensar na negação do $\boldsymbol{e u}$ como unidade constituída, numa fuga que se enovela em um desafio de outrar-se, a qual confere o desafio do autor em querer encontrar nos heterônimos essa unidade pretendida.

As multifacetadas formas com que os heterônimos foram criados demonstram a angústia em procurar desvendar a vida e a morte, a perfeição e a imperfeição, a alegria e a tristeza, a humanidade e a divindade.

A chamada "crise de identidade" é vista como parte de um processo mais amplo de mudança, que desloca a estrutura das sociedades modernas e abala as estruturas vigentes que davam aos indivíduos uma ancoragem estável no mundo social.

O sintoma da crise é, portanto, o declínio das velhas identidades, pautadas em paradigmas de classe, gênero, sexualidade, etnia, raça e nacionalidade, que representam de algum modo a marca da estabilização do mundo social, o que fez gerar o surgimento de novas identidades e a fragmentação do indivíduo.

O conceito de identidade pessoal também passa por mudanças na medida em que a visão de um sujeito integrado se desfaz. Essa perda de um "sentido de si" ocasionou o que se denomina “deslocamento ou descentralização do sujeito" (NIETZSCHE, 1999, p.31). O que gera a crise de identidade é a ação conjunta de um duplo deslocamento, o que refletirá a descentralização dos indivíduos tanto do seu lugar no mundo social e cultural quanto de si mesmos.

A identidade é a responsável pela estabilização e localização do sujeito. $\mathrm{Na}$ modernidade é possível encontrar um sujeito fragmentado, sem identidade fixa, que é formado e transformado continuamente em relação às formas pelas quais somos representados ou interpelados nos sistemas culturais vigentes. Assim, o homem contemporâneo vive em permanente confronto com uma multiplicidade que supõe uma gama de identidades possíveis e cambiantes, com as quais temporariamente pode se identificar.

É neste contexto que literatura, pelo seu caráter eminentemente discursivo, tem sido o espaço em que as localizações do sujeito e as construções da identidade afloram, permitindo-nos uma visualização clara de como os indivíduos modernos concebem e constroem suas identidades. 
Conforme Renato Mezan a sociedade precisa criar não somente obstáculos à realização dos desejos, mas também canais através dos quais o sujeito possa dispor de um estado psíquico interno; e uma das partes desse espaço interno é a identidade. O poder não é apenas uma instância que reprime e proibe; ele faz surgir, incita, produz comportamentos, como mostram estudos de Michel Foucault. Entre esses comportamentos, está a relação do indivíduo consigo próprio, que é função de certas maneiras de sentir, de agir e de pensar. (MEZAN, 2002, p.57). Tal afirmação nos faz adentrar em outra questão trabalhada neste artigo: a alteridade. Tendo Fernando Pessoa raízes judaicas, faz-se necessário esclarecer que a heteronímia, o torna-se outro, ecoa na obra pessoana; o judeu, após a barbárie das Cruzadas, passou a encarnar de maneira privilegiada a figura do Outro, do inimigo por excelência: diferente por sua religião, seus costumes e símbolo da ameaça.

Este artigo propõe uma breve análise da desconstrução do eu a partir do heterônimo Álvaro de Campos, pois, segundo Eduardo Lourenço, é através de Álvaro de Campos que "Pessoa oferece-se em comédia a tragédia da sua glacial solicitude e em tragédia a comicidade dolorosa de uma existência que não encontra em parte alguma nem em nada, remédio contra a angústia torrencial que o devasta" (LOURENÇO, 2003, p.176).

$\mathrm{Na}$ Ode Marítima, nota-se um viés trágico de Ser-vos as vítimas, apesar da tentativa de distanciamento, o delírio é complacente:

Ah, não sei que, não sei quanto queria eu ser de vós!

Não era só ser-vos a fêmea, ser-vos as fêmeas, ser-vos as vítimas, Ser-vos as vítimas - homens, mulheres, crianças, navios - , Não era só ser a hora e os barcos e as ondas., Para poder encher toda a medida da minha fúria imaginativa. Para poder nunca esgotar os meus desejos de identidade Com a calda, e o tudo, e o mais- que tudo das vossas vitórias. Ode Marítima. (PESSOA, 1993, p.103).

Há, nesta desconstrução, momentos em que o próprio eu-lírico se contradiz e se esforça para entender o processo de desassujeitamento:

Multipliquei-me, para me sentir Para me sentir, precisei sentir tudo, Transbordei, entreguei-me, E há em cada canto da minha alma Um altar a um deus diferente (Passagem das horas, Álvaro de Campos) 
Eu? Mas sou eu o mesmo que aqui vivi, e aqui voltei, E aqui tornei a voltar, e a voltar

E aqui de novo tornei a voltar?

Ou somos todos os Eu que estivesse aqui ou estiveram, Uma série de contas - entes ligadas por um fio-memória, Uma série de sonhos de mim de alguém de fora de mim? (PESSOA, 1993, p.378).

A desconstrução, o desfazer-se é próprio da arte, Pessoa já conceituava que “[...] tudo que é vivo subsiste pelo equilíbrio de duas forças - a de integração e a de desintegração [...], a que desintegra faz viver e morrer; a que integra faz morrer e viver. Uma insiste, e outra subsiste" (PESSOA, 2005, p.238). Sendo assim, a partir do momento em que a literatura abandona o pensamento do interior e se dirige ao próprio ser da linguagem, a angústia de não-ser se esvai para fora de si próprio, lançando Pessoa à transcendência, à solitude, ao egocentrismo, à ação Patriótica e à expressão literária.

Se o real já não tem uma consciência ordenadora, deveremos então pensar que "o outro" é sujeito único da arte? É possível que não: se a criação artística traz necessariamente consigo a desestruturação do eu, conduz também logicamente à construção de outros "sujeitos", estes representam outros tantos modos de sentir. Pois cada modo de sentir, ou até cada sensação, deve "encarnar-se" (palavra utilizada por Bernardo Soares no Livro do desassossego) numa "alma". Não há sujeito artístico porque este se esvai, mas "uma multiplicidade; não há apenas um devir outro, mas uma pluralidade indefinida. Assim cumpre-se o que se prescreve em: sentir tudo de todas as maneiras" (GIL, p.37).

Recordamos os versos do poema "Afinal":

Afinal a melhor maneira de viajar é sentir.

Sou um monte confuso de forças cheias de infinito Tendendo em todas as direções para todos os lados do espaço Meu corpo é um centro dum volante estupendo e infinito Em marcha sempre vertiginosamente em torno de si, cruzando-se em todas as direcções com outros volantes, Que se entrepenetram e misturam, porque isto não é no espaço Mas não sei onde espacial de uma maneira - Deus. (PESSOA, 2003, 398).

As "direcções" marcam a multiplicidade dos pontos de vista possíveis: as forças, os volantes avançam em todas as "direcções" que indicam outras tantas maneiras de sentir, e 
Deus, longe de se unificar, permite que coexistam todas, se "entrepenetrem" e se misturem na sua incoerência, na sua irracionalidade, na sua sem-razão. Eis o que diz Álvaro de Campos, com extrema clareza:

Quanto mais eu sinta, quanto mais eu sinta como várias pessoas, Quanto mais personalidade eu tiver, Quanto mais intensamente, estridentemente as tiver, Quanto mais simultaneamente sentir com todas elas, Quanto mais unificadamente diverso, dispersadamente atento, Estiver, sentir, viver, for, Mais possuirei a existência total do universo, Mais completo serei pelo espaço inteiro fora. Mais análogo serei a Deus, seja ele quem for, Porque, seja ele quem for, com certeza que é Tudo, E fora d'Ele há só Ele, e Tudo para Ele é pouco.

Cada alma é uma escada para Deus, Cada alma é um corredor - Universo para Deus, Cada alma é um rio correndo por margens de Externo Para Deus e em Deus com um sussurro soturno. (PESSOA, 2003, p.398).

O sujeito da escrita não é portanto nem Fernando Pessoa poeta, tampouco Campos que, objetivamente, não existe. Possivelmente a condição para que os versos fossem escritos que se implica no desaparecimento do sujeito da escrita "Fernando Pessoa" (que modifica radicalmente a sua escrita, o seu estilo, a sua identidade no pensar e no sentir).

No âmbito formal, encontramos as implicações da constituição oximórica em alguns trechos do poema, como em Quanto mais unificadamente diverso, dispersadamente atento. Nestes versos há a tensão entre a existência e a inexistência (único e diverso/disperso e atento).

De maneira mais precisa, se no interior do empreendimento literário todo o seu contexto é poeticamente construído, e, portanto, detém como substância a própria linguagem da poesia, é com o recurso lingüístico dos oxímoros, agora numa relação metonímica entre essa figura de linguagem e todo o seu projeto literário, que Álvaro de Campos constrói um mundo de forças antagônicas que se embatem assim como os termos de um oxímoro. Oxímoro é um termo usado também na Psicologia que caracteriza uma personalidade contraditória ou ambivalente: alguém, por exemplo, ferido do ponto de vista psicológico, mas suficientemente resistente que é capaz de esperar, e alcançar, melhores dias. 
Em ensaios a respeito da poesia de Fernando Pessoa, Eduardo Lourenço propõe que Pessoa não é simplesmente o poeta da melancolia e da angústia diante da morte, como possa parecer. Mas, se de muitos textos seus emana uma tristeza profunda, é preciso tentar entender o empreendimento poético de Pessoa como uma tentativa de oferecer sentido para a existência.

Pessoa viveu profundamente a tragédia do seu tempo, de que Deus estava morto. Para livrar-se dela desejou a inconsciência, idealizou um poeta cujos pensamentos são todos sensações, fez-se plural. Procurou de diversas formas fragmentar-se para sobreviver à fragmentação de seu tempo. Deparou-se com o nada em todas as direções para onde foi. A sua poesia é oriunda desse encontro com o vazio.

Anseio com uma angústia de fome de carne

O que não sei que seja -

Definitivamente pelo indefinido. (PESSOA, 2003, p.399).

É nos percalços de uma construção falhada de si que o eu lírico adquire não só uma impossibilidade de alcançar o que se almeja, mas, notadamente, de deslegitimar a coisa desejada, transformando o tudo em que falhou em nada, e, portanto, conferindo mesmo àquilo que poderia vir a desejar numa refinada forma de desatualização, pois, em si mesmo, rumina uma intensa intranquilidade que ele justifica como cansaço, não-agir, em razão de não aceitar o seu fracasso no mundo.

Surge, neste instante, a necessidade de se mencionar o princípio do judaísmo: a estrangeiridade, a diferença, aquilo que escapa, já que a estranheza do Deus judaico é absolutamente conforme a estranheza de seu povo. Acredita-se que a religião judaica acentua a questão da alteridade porque a experiência da Diáspora (dispersão), do êxodo, a prevalência do nomadismo e da errância e, também, a experiência de um Deus que se apresenta como pura ausência, pura diferença, conflita com a idéia de identidade, anunciando a prevalência da alteridade sobre a identidade.

A famosa frase de Nietzsche sobre a morte de Deus aponta para esta mesma questão. Deus existia antes como um princípio organizador, como aquele que dava o sentido final e transcendente à vida.

Quando já não há Deus nem deuses, a realidade deixa de fazer sentido, torna-se puro caos e acaso. A única certeza que permanece é a morte. Assim transparece Álvaro de 
Campos: repugna-lhe o agir, pois a sua ação não pode alterar nada na essência eterna das coisas.

Pessoa viveu a aurora desse tempo. Ele buscou a salvação numa vida inventada. Inventou vários poetas e até uma pátria. Cada um de seus heterônimos exprime uma forma de se relacionar com a finitude, um novo modo de ser. Não satisfeito com a invenção de várias vidas para si, Pessoa inventou uma vida mais condizente para a pátria portuguesa. Não é por acaso que se encontram em Mensagem dois versos que são chave para o entendimento do seu pensamento e da sua poesia: "Em baixo, a vida, metade/ De nada, morre".

Para dar conta de sua angústia existencial de homem que vive o tempo da fragmentação, Pessoa multiplicou-se em heterônimos, buscando dotar cada um deles de uma visão de mundo própria.

Doravante, a valorização excessiva do "sentido histórico" é, na opinião de Nietzsche, um dos responsáveis por levar o homem moderno ao niilismo e à decadência, porque nada faz senão tornar doente e pessimista a cultura moderna.

Segundo Foucault (MACHADO, p.65), a modernidade se inaugurou no século XIX quando o homem se deu conta do artifício da linguagem. Se até então o pensamento hegemônico era de que linguagem dizia a verdade do mundo, com a emergência das ciências humanas e a invenção do homem como um objeto de estudo, a linguagem passou a ser um espelho do mundo.

Pessoa é o poeta do não-ser imaginário. A poesia de Pessoa figura de um profundo pesar pela consciência da finitude e do sentimento de falta de sentido da vida.

A heteronímia é a busca de sentidos outros para a vida. Doravante, o empreendimento de Pessoa deixa de ser visto apenas como renúncia, tornando-se uma espécie de salvação.

Há, portanto, de se ver em Pessoa um autor de autores, um autor multipolar. E se não reduzirmos a autonomia de cada heterônimo, a autoria em Fernando Pessoa exibe a forma de um diálogo múltiplo e descentrado.

O que a despersonalização pessoana nos mostra é o nada que extrapola a existência humana. Ao invés de expressar uma suposta subjetividade, Pessoa encena a radical alteridade ao dar forma a distintas personalidades poéticas. Trata-se do desaparecimento do 
“eu" para fazer surgir a persona, a máscara. É no existir que o homem vai assumindo o seu perfil, é no que não se é que se abre a possibilidade de vir-a-ser.

As distintas personagens deste "drama em gente", como ele mesmo tratava a multiplicidade de vozes em sua obra, devem ser tratadas como entidades autônomas.

O que concerne autonomia às distintas figuras pessoanas é, por um lado, o modo distinto como a linguagem nelas se manifesta - "vôo outro-eis tudo", profere o poeta ortônimo.

Cada heterônimo assume uma postura diversa. Campos, aqui analisado, experimenta as limitações do pensar para dar conta da fragilidade existencial ("Ser o que penso? Mas penso ser tanta coisa!"), oscila entre o anseio de totalidade e heroísmo de ser já, total.

Sou um formidável dinamismo obrigado ao equilíbrio

De estar dentro do meu corpo, de não transbordar da minh'alma.

Ruge, estoira,vence,quebra,estrondeia,sacode,

Freme,treme,espuma,venta,viola,explode, Perde-te,transcende-te,circunda-te,vive-te,rompe e foge, Sê com todo o meu corpo todo o universo e a vida, Arde com todo os meu corpo o meu ser todos os lumes e luzes, Risca com toda a minha lama todos os relâmpagos e fogos, Sobrevive-me em minha vida em todas as direcções! (PESSOA, 2003, p.326).

Álvaro de Campos é um sujeito do inconsciente que advém a Fernando Pessoa? Fernando Pessoa é sujeito em Álvaro de Campos? São especulações que não têm outra finalidade a não ser a de serem especulações.

Pois que, por outro lado, Álvaro de Campos é sujeito pensante. Os pensamentos o atormentam, o inquietam. Não lhe trazem soluções, nem apontam caminhos. O pensamento não é finalizado, não tem fim. $O$ caminho não tem direção exata: pode ser qualquer um, todos e, ao mesmo tempo, nenhum.

Nada me prende a nada.

Quero cinqüenta coisas ao mesmo tempo.

Anseio com uma angústia de fome de carne

O que não sei que seja -

Definitivamente pelo indefinido...

Durmo irrequieto, e vivo num sonhar irrequieto

De quem dorme irrequieto, metade a sonhar. (PESSOA, 2003, p.327). 
Pensamentos que apontam dúvidas, mostram-nos a indecisão de um homem possível. Desconhecimento. Não há definições. O sujeito não se conhece. Tem consciência do desconhecimento de si próprio. Alguma coisa angustia e faz falar Álvaro de Campos, mas não se sabe o quê, porque, uma vez enunciada, apenas se dispersa e não se reúne, nunca. Eis o sujeito descentrado.

\section{Referências bibliográficas}

ASSOUN, Paul-Laurent. Introdução à Epistemologia Freudiana. Ed.Imago: RJ,1983.

COELHO, António Pina. Os fundamentos filosóficos da obra de Fernando Pessoa (Vol. I e II). Lisboa: Ed. Verbo, 1971.

GIL, José. Fernando Pessoa ou A Metafisica das sensações. Lisboa:Relógio d'água, s/d.

LEVINAS, Emmanuel. Novas interpretações talmúdicas. Rio de Janeiro: Ed. Civilização Brasileira, 2002.

LOURENÇO, Eduardo. Fernando Pessoa Revistado. São Paulo: Ed. Companhia das Letras, 2003.

MACHADO, Roberto. Foucault, a filosofia e a literatura. Rio de Janeiro: Jorge Zahar Editor, 2005.

MARIGUELA, Márcio. Foucault e a destruição das evidências. Ed. UNIMEP, 1995.

MEZAN, Renato. Psicanálise e judaísmo. Ressonâncias. Rio de Janeiro: Editora Imago. $2^{\mathrm{a}}$ Edição.

MOREIRA, Jacqueline de Oliveira. "Do Problema da Alteridade no pensamento freudiano:uma construção". PUC-SP. Disponível em: www.pucminas.com.br. Acessado em 22 de maio de 2007.2003.

NIETZSCHE, Friedrich. Coleção Os Pensadores. São Paulo: Editora Nova Cultural, 1999.

OSAKABE, Haquira. Fernando Pessoa resposta à decadência. Paraná: Editora Criar, 2002.

PESSOA, Fernando. Álvaro de Campos. Livro de Versos. Edição Crítica. Introdução, transcrição e notas de Teresa Rita Lopes Lisboa: Ed. Referência-Estampa, 1993. . Obra em Prosa. Rio de Janeiro: Ed. Nova Aguilar, 2005. 